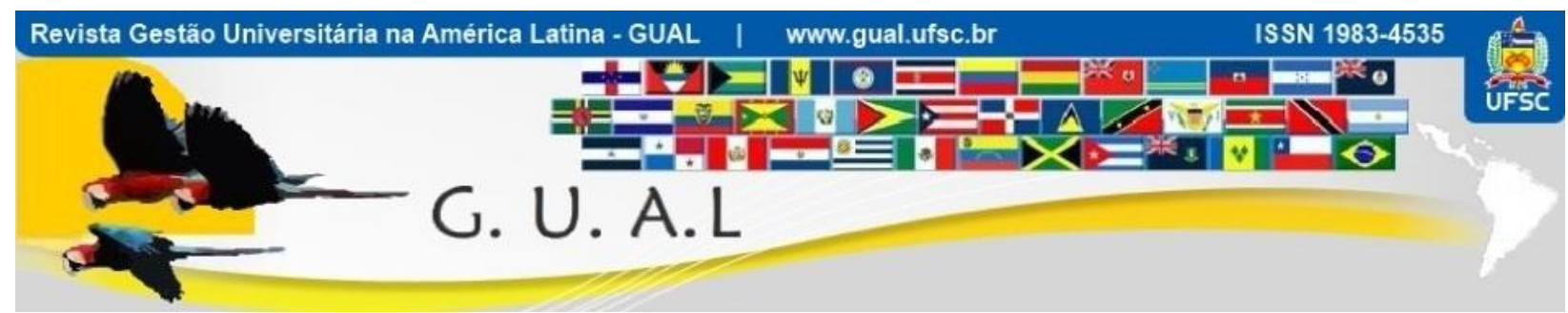

DOI: http://dx.doi.org/10.5007/1983-4535.2017v10n4p252

\title{
MOBILIDADE ACADÊMICA: UM ESTUDO COMPARATIVO NO CONTEXTO DE INSTITUIÇÕES UNIVERSITÁRIAS
}

\section{ACADEMIC MOBILITY: A COMPARATIVE STUDY IN THE CONTEXT OF UNIVERSITY INSTITUTIONS}

Yana Paula Pereira, Bacharel Universidade do Extremo Sul Catarinense - UNESC

yanapereira7@hotmail.com

Izabel Regina de Souza, Mestre Universidade do Extremo Sul Catarinense - UNESC izabel@unesc.net

Andrigo Rodrigues, Mestre Universidade do Extremo Sul Catarinense - UNESC andrigo@unesc.net

Cristiane Dias, Especialista Universidade do Extremo Sul Catarinense - UNESC cris.dias@unesc.net

Recebido em 25/novembro/2016

Aprovado em 16/outubro/2017

Sistema de Avaliação: Double Blind Review

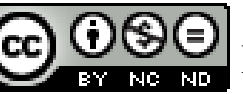

Esta obra está sob uma Licença Creative Commons Atribuição-Uso. 


\title{
RESUMO
}

Este trabalho tem como objetivo identificar quais as convergências encontradas nas ações de mobilidade acadêmica em duas instituições de educação superior de diferentes países. Em relação à metodologia utilizada, para fins de investigação a pesquisa caracterizou-se como descritiva, e quanto aos meios de investigação, como pesquisa bibliográfica e de campo. A população-alvo do trabalho foram os gestores dos setores de Relações Internacionais das instituições de ensino e os acadêmicos que realizaram mobilidade de 2006 a 2015. Para esta pesquisa, os dados foram oriundos de dados primários e secundários, e a técnica de coleta de dados foi qualitativa, havendo dois instrumentos de coleta de dados: um questionário para os acadêmicos e uma entrevista semi-estruturada com os gestores. A análise do discurso foi realizada quanto a abordagem qualitativa. A pesquisa permitiu com que os acadêmicos sugerissem melhorias para suas Instituições de ensino a partir de suas percepções das políticas de mobilidade da instituição. Averiguou-se que as convergências encontradas nas ações de mobilidade acadêmica nas instituições são principalmente os acordos bilaterais que ambas possuem com instituições estrangeiras, o perfil de acadêmicos que realizam programas de mobilidade e o fato de conseguirem contemplar os mesmos com bolsas de mobilidade.

Palavras chave: Mobilidade Acadêmica. Internacionalização. Universidade.

\begin{abstract}
This study aims to identify the convergences in academic mobility actions in two higher education institutions from different countries. Regarding the methodology used for research purposes of research was characterized as descriptive and as the means of research, such as literature and field research. The work target population were managers of the sectors of International Relations of educational institutions and academics that made mobility from 2006 to 2015. For this research, the data were derived from primary and secondary data, and the data collection technique it was qualitative, with two data collection instruments: a questionnaire for academics and a semi-structured interview with managers. The discourse analysis was conducted as a qualitative approach. The research allowed that scholars suggest improvements to their educational institutions from their perceptions of the institution's mobility policies. It was found that the similarities found in academic mobility actions in the institutions are mainly bilateral agreements that both have with foreign institutions, the academic profile that perform mobility programs and the fact achieve the same look with mobility grants.
\end{abstract}

Keywords: Academic Mobility. Internationalization. Higher Education Institution. 


\section{INTRODUÇÃO}

O processo de internacionalização do ensino superior está se tornando cada vez mais importante para a sociedade em geral. Este processo é realizado há décadas, desde que as universidades começaram a ser formadas por professores de diferentes países, permitindo que compartilhassem seus conhecimentos e adquirissem mais do país em que estavam lecionando. Atualmente, a mobilidade acadêmica é de extrema importância, visto que a globalização estreitou os laços entre os países e quebrou barreiras, fazendo com que o conhecimento de cada região ou país seja levado para outras partes do mundo (DUARTE; DE LIMA JÚNIOR; BATISTA, 2008).

A competitividade entre os profissionais está aumentando cada vez mais, assim como o avanço tecnológico e a globalização da economia, o que gera a necessidade das pessoas possuirem uma ótima formação profissional para se destacarem e se tornarem ótimos profissionais, e as instituições de ensino superior estão encarregadas de oferecer isso (DOMINGUES; RABOCH, 2008).

Além de a globalização exigir mais qualidade na formação do profissional e dificultado de certa forma seu sucesso na carreira profissional, por conta dos inúmeros avanços e dificuldades encontradas na economia atualmente, ela fez com que os países se ligassem de alguma forma no quesito educacional, fazendo com que a internacionalização do ensino ocorra mais facilmente (VILALTA, 2012).

A internacionalização do ensino pode ser alcançada de diversas formas, como por exemplo pela mobilidade acadêmica, pela contratação de professores de diferentes países, pela investigação científica e tecnológica formada por cooperações entre países, entre outros. Há inúmeros acordos entre instituições de diferentes países, acordos entre governos, bolsas oferecidas pelos países, organizações e cooperações internacionais que possuem o objetivo de internacionalizar o ensino, permitindo o compartilhamento e transferência de conhecimentos e experiências entre diferentes países (STALLIVIERI, 2002).

Desta forma, a presente pesquisa teve como objetivo geral identificar quais as convergências encontradas nas ações de mobilidade acadêmica em duas instituições de educação superior de diferentes países. 


\section{MARCO TEÓRICO}

\subsection{ENSINO SUPERIOR}

A universidade possui um importante papel social, gerando e transmitindo o conhecimento humano pelo mundo. As primeiras instituições surgiram ainda durante a Idade Média, na Europa Ocidental, e aos poucos disseminaram-se pelos demais países do mundo (BOHRER et al,2008).

Tomando como base autores como Santos e Almeida Filho (2012), Rossato (2011) e Bohrer et al (2008), que escrevem sobre a universidade e suas origens, as primeiras universidades surgiram durante o século XI, sendo a de Bolonha a mais antiga, fundada em 1088, e a Universidade de Paris, criada no século XII, no ano de 1090 ou 1170 (data incerta).As instituições universitárias são tão importantes que influenciaram alguns fatos históricos. Pode-se citar como exemplo a contribuição das universidades alemãs para a Reforma Protestante no século XVI e a união de membros e alunos da Universidade de Paris, que juntos formaram a Companhia de Jesus no período de Contra-Reforma.

Já na América Latina, as universidades surgiram no início do século XVI em países como Peru, México, Cuba, Chile e outros países, e funcionavam de acordo com o sistema universitário espanhol (TRINDADE, 2000)

No Brasil, de acordo com Santos e Almeida Filho (2012), houve uma resistência à implantação de instituições de ensino superior. Como era colônia de Portugal desde a descoberta em 1500, viveu sob o regime imperial até 1922, quando houve a Proclamação da República. Inicialmente, durante este período, os únicos ensinamentos na Colônia eram relacionados à expansão da fé católica na mesma.

Foi a partir de 1930, depois que ocorreram algumas modificações no ensino superior, que as Universidades realmente foram fundadas no Brasil. Pode-se citar a Universidade de São Paulo, em 1934, e a Universidade do Distrito Federal, no Rio de Janeiro. Santos e Cerqueira (2009) explicam que os sucessivos acontecimentos políticos no Brasil nas décadas seguintes influenciaram as instituições de ensino superior, originando o sistema de ensino superior que funciona hoje em dia no país.

Atualmente, segundo Stallivieri (2007), o ensino superior brasileiro é classificado em instituições públicas e privadas. As instituições públicas são gratuitas para os alunos e são financiadas pelo poder público do país (nível municipal, estadual ou federal), enquanto as 
instituições privadas são financiadas pelos próprios alunos através do pagamento de mensalidades, podendo ser comunitárias, confessionais, filantrópicas ou particulares.

As Universidades Federais, apesar de gratuitas, são de mais difícil acesso quando comparadas a maioria das universidades privadas, visto que o aluno precisa ter um ótimo desempenho no vestibular para o ingresso na mesma. Já em relação ao número de ingressos, as instituições particulares de ensino superior possuem um número muito maior que as instituições públicas (SAMPAIO; GUIMARÃES, 2009).

As universidades privadas contam com alguns programas que visam ajudar os acadêmicos com menor poder aquisitivo a se manter no ensino superior. Pode-se citar como exemplos o Fundo de Financiamento Estudantil (FIES), que consiste em um financiamento do valor parcial ou total do curso superior e o acadêmico só precisa dar início ao pagamento do financiamento depois de um ano e meio de formado, e o Programa Universidade para Todos (Prouni), um programa que beneficia aqueles que não têm condições de arcar com os custos universitários e tiveram bom desempenho no Enem com bolsas de estudo nas instituições superiores que aderiram ao programa. O Enem tem como objetivo medir os conhecimentos que o aluno obteve ao terminar o ensino médio, e além de ser usado para o Prouni, substitui vestibulares em várias instituições de ensino superior (BRASIL, 2015b).

Em Portugal a implantação do ensino superior foi diferente. Antes mesmo da criação das Universidades em Portugal, os membros de instituições religiosas frequentavam Universidades em outros países da Europa, com o objetivo de melhorar o ensino em suas escolas. A Universidade de Coimbra, fundada em 1290, foi a primeira do país, e acompanhou as reformas em relação ao ensino superior do país desde sua fundação (JACA; FREITAS, 2008).

Posteriormente, após a proclamação da República em Portugal, no ano de 1911 foram fundadas as Universidades de Porto e Lisboa, que ganharam autonomia e recursos para desenvolvimento (PORTUGAL, 2003).

No país o sistema de educação superior também é classificado em instituições públicas e instituições privadas. Ao contrário do Brasil, o maior número de matrículas no ensino superior são em instituições públicas, com cerca de $83 \%$, enquanto o setor privado conta com cerca de apenas $17 \%$ das matrículas. (PORTUGAL, 2003) 


\subsection{INTERNACIONALIZAÇÃO DO ENSINO SUPERIOR}

A educação superior, com a globalização, é vital para o crescimento de países desenvolvidos ou em processo de desenvolvimento, pois cumpre a função de produzir e propagar conhecimentos. Este crescimento gerou a abertura dos mercados, diminuindo as barreiras entre os países e permitindo um fluxo de conhecimento entre as nações nunca visto anteriormente. Este fenômeno (globalização), fez com que o conhecimento se tornasse internacional, fazendo com que as instituições de ensino superior, responsáveis pela formação dos cidadãos, precisassem se adequar às mudanças proporcionadas pelo mesmo (FRANKLIN, 2014).

Segundo Altbach e Knight (2007), existem vários tipos de internacionalização educacional. Os autores citam a internacionalização dos países em desenvolvimento, que visam o prestígio e o melhoramento de qualidade e perfil do corpo discente; a internacionalização europeia, que ocorre dentro dos países da União Europeia; a internacionalização tradicional, proveniente de universidades centenárias e por fim a internacionalização individual, onde os acadêmicos realizam o intercâmbio particularmente, movimentando a maior parte da renda da educação internacional.

Teichler (2004) afirma que o processo de internacionalização do ensino superior está relacionado com a globalização, porém também com a europeização, visto que a internacionalização no espaço europeu ocorre intensamente entre os países da União através da cooperação, integração, mobilidade e estrutura do espaço europeu.

Na União Europeia, em 1999 foi assinada a Declaração de Bolonha, que visava, em um prazo de 10 anos, estabelecer um Espaço Europeu de Ensino Superior (EEES). O EEES tinha como objetivos: o aumento de estudantes provenientes de outros países para suas universidades; o incentivoda mobilidade de seus estudantes entre os países europeus; conseguir uma estrutura equivalente nos seus cursos superiores, com graus acadêmicos compatíveis e comparáveis; o estabelecimento de um sistema internacional de créditos acadêmicos, os European Credit Transfer System (ECTS) e consequentemente um fortalecimento no bloco (SIEBIGER, 2010).

Atualmente o Processo de Bolonha se faz presente não só na União Européia, mas também em outros países, contabilizando 47 países ao total. Na União, foi consolidado o programa ErasmusMundus, onde os alunos do ensino superior europeu podem realizar um período de seus estudos em outra instituição de ensino dentro da União. Seus objetivos são a 
consolidação de uma dimensão europeia de educação, melhorar os procedimentos relativos à validação e reconhecimento acadêmicos dos diplomas e fortalecer a cooperação entre os estabelecimentos de ensino superior no continente (UNIVERSIDADE NOVA DE LISBOA, 2007).

Portugal é um dos países da Europa que possui um ambiente favorável para o acolhimento de alunos em mobilidade acadêmica, suas instituições de ensino superior apostam na internacionalização como estratégia, pois já perceberam a importância que esta abertura pode proporcionar para o país, tanto politicamente, economicamente quanto educacionalmente (UNIVERSIDADE NOVA DE LISBOA, 2007).

Um dos benefícios que os estudantes portugueses possuem ao realizar mobilidade acadêmica em outros países é a facilidade de reconhecimento e validação de graus e diplomas estrangeiros, o que impulsiona a mobilidade dos cidadãos portugueses (PORTUGAL, 2014).

O país possui um grande número de estudantes internacionais em suas instituições, principalmente brasileiros, que estão distribuídos em instituições públicas e privadas de ensino superior, sendo $81 \%$ em instituições públicas e $19 \%$ em instituições privadas. Esses números só são possíveis graças aos acordos de cooperação internacional realizados pelo Governo e instituições de ensino superior portuguesas com universidades estrangeiras. Com o Governo do Brasil, pode-se citar o Programa Ciência sem Fronteiras, que recentemente se restringiu a mestrados e doutorados no país; o Programa de Licenciaturas Internacionais, que objetiva a formação de professores; e acordos particulares entre universidades, onde os custos financeiros ficam por conta do acadêmico (PORTUGAL, 2014).

No Brasil, a internacionalização do ensino superior se iniciou de uma forma diferente. Segundo Lima e Riegel (2013), até o ano de 1990, no Brasil, a mobilidade internacional só acontecia pelo fato de ser financiada por agências públicas que incentivavam a pesquisa, porém somente para acadêmicos que estivessem matriculados na pós-graduação. Porém com o passar dos anos, a internacionalização do ensino se mostrou cada vez mais importante, fazendo com que as famílias poupassem e arcassem com os custos dos estudos dos filhos em um outro país.

A partir do momento em que o Brasil emergiu como potência mundial, começou a ser visto com outros olhos pelos outros países, e conquistou maior influência no cenário mundial. Com isso, suas universidades, além de receber acadêmicos estrangeiros, começaram a se abrir e desenvolver um interesse por parcerias e acordos de cooperação com instituições de ensino 
superior estrangeiras, consolidando a internacionalização de seu ensino superior (SANTOS; ALMEIDA FILHO, 2012).

Uma das primeiras instituições de ensino superior que firmaram acordos com o Brasil foi a Universidade de Coimbra, de Portugal. O primeiro programa de mobilidade acadêmica a entrar em vigor foi o Programa de Licenciaturas Internacionais, financiado pela Coordenação de Aperfeiçoamento de Pessoal de Nível Superior (CAPES), e também contou com o apoio do Banco Santander, que possuía um convênio com a Universidade de Coimbra.

Outro programa é o Ciência sem Fronteiras $(\mathrm{CsF})$, um programa de intercâmbio tem a finalidade de consolidar, expandir e internacionalizar a ciência, tecnologia, inovação e

competitividade do Brasil através da mobilidade de acadêmicos, e é financiada pelo Governo Federal (BRASIL, 2015a).

Atualmente, há também programas de bolsas de estudo financiadas pelo Santander Universidades, que junto com o Ciência sem Fronteiras, são os principais programas de intercâmbio que oferecem bolsas no Brasil (SANTANDER, 2016).

\section{PROCEDIMENTOS METODOLÓGICOS}

Esta pesquisa tem como população-alvo os gestores das instituições de ensino e os acadêmicos que realizaram mobilidade acadêmica de 2006 a 2015 nas duas instituições de ensino superior analisadas.

A coleta de dados aconteceu em dois momentos: inicialmente foi realizado uma entrevista semi-estruturada com os gestores do setor de Relações Internacionais das instituições em estudo. Com o gestor da instituição de Portugal, a entrevista aconteceu por meio eletrônico. Já com o gestor da instituição brasileira a entrevista foi realizada pessoalmente. No segundo momento foi realizado uma pesquisa com os acadêmicos das duas instituições, através de questionário estruturado e com perguntas fechadas e abertas aplicado via Google Docs, para conhecer a motivação e expectativas dos acadêmicos em mobilidade.

No questionário para os acadêmicos, buscou-se primeiramente definir seu perfil através de dados como a idade, período de intercâmbio, e país de destino. As questões abertas permitiram mostrar o ponto de vista dos acadêmicos sobre as políticas de sua instituição de ensino superior em relação a internacionalização do ensino.

Para fins de entendimento, as instituições serão apresentadas da seguinte maneira: Letra A intitula a instituição Brasileira, letra B intitula da instituição Portuguesa. 
Conforme dados disponibilizados pelos gestores entrevistados, 59 acadêmicos da Instituição A realizaram mobilidade acadêmica, e cerca de 1200 alunos da Instituição B também participaram de programas de mobilidade. Para o envio do link do questionário para os acadêmicos, obteve-se uma relação de nomes e endereços eletrônicos dos alunos da Instituição A, por onde foi possível encaminhá-lo aos mesmos. Quanto aos acadêmicos da Instituição B, o setor de Relações Internacionais da instituição se disponibilizou a enviar o link do questionário a estes alunos, visto que seria mais provável que respondessem o questionário a pedido da Universidade.

Dos questionários enviados, obteve-se o retorno de 15 acadêmicos da Instituição A e 26 acadêmicos da Instituição $\mathbf{B}$, os quais foram numerados e não identificados a fim de preservá-los.

\section{RESULTADOS E ANÁLISE}

\subsection{CARACTERIZAÇÃO DAS UNIVERSIDADES}

\subsubsection{Instituição A}

A Instituição A, localizada no sul do Brasil, surgiu de uma mantenedora, a qual foi criada em 22 de junho de 1968, e tem como visão de futuro"Ser reconhecida como uma Universidade Comunitária, de excelência na formação profissional e ética do cidadão, na produção de conhecimentos científicos e tecnológicos, com compromisso sócio-ambiental". Além dos 36 cursos de graduação e 10 tecnológicos, a instituição oferece 31 cursos de pósgraduação, investe em projetos de pesquisa e extensão e ainda tem um colégio integrado à Universidade (UNIVERSIDADE DO EXTREMO SUL CATARINENSE, 2016).

\subsubsection{Instituição B}

A atual Instituição B, localizada no sul de Portugal, é resultado da união de duas instituições: a Universidade, que teve seu primeiro Reitor nomeado no ano de 1982, e o Instituto Politécnico da cidade em que está situada. De acordo com seu Estatuto, a Instituição B tem como alguns de seus fins fundamentais a investigação científica de alto nível e o desenvolvimento experimental; a promoção da internacionalização de suas atividades; formação científica, técnica, profisssional, humanística e cultural, entre outros objetivos.

Atualmente a Instituição B é diferente das demais universidades, visto que possui o Ensino Superior Universitário e o Politécnico, e conta com: 52 cursos de graduação e 5 com 


\section{MOBILIDADE ACADÊMICA: UM ESTUDO COMPARATIVO NO CONTEXTO DE INSTITUIÇÕES UNIVERSITÁRIAS \\ DOI: http://dx.doi.org/10.5007/1983-4535.2017v10n4p252}

mestrados integrados, 23 cursos de pós graduação. 67 mestrados e 25 doutorados, além de 14 cursos técnicos superiores profissionais. (UNIVERSIDADE DO ALGARVE, 2016).

\subsection{ENTREVISTA COM OS GESTORES}

Para melhor visualização e comparação das instituições em estudo, as respostas obtidas nas entrevistas com os gestores dos setores de Relações Internacionais estão representadas no Quadro 1.

Quadro 1 Entrevista com os gestores dos setores de Relações Internacionais das Instituições em estudo.

\begin{tabular}{|c|c|}
\hline Instituição A & Instituição B \\
\hline \multicolumn{2}{|c|}{ Quanto a promoção de programas de incentivo } \\
\hline $\begin{array}{l}\text { Através do site da Universidade; recepção dos calouros; } \\
\text { folders em pontos de visibilidade da instituiçãa.Se o } \\
\text { edital é direcionado para um curso, a Coordenação dos } \\
\text { cursos divulga aos alunos por e-mail. }\end{array}$ & $\begin{array}{l}\text { Através de Sessões de esclarecimento; informação na } \\
\text { página Web; pedidos aos Coordenadores de } \\
\text { Mobilidade que divulguem a informação da página. }\end{array}$ \\
\hline \multicolumn{2}{|l|}{ Quanto aos tipos de bolsas oferecidas } \\
\hline Santander e Ciência sem Fronteiras. & Bolsas Erasmus. \\
\hline \multicolumn{2}{|l|}{ Quanto as parcerias para mobilidade acadêmica } \\
\hline $\begin{array}{l}\text { A instituição possui } 29 \text { Universidades parceiras } \\
\text { atualmente, distribuidas em } 15 \text { países. }\end{array}$ & $\begin{array}{l}\text { A instituição possui cerca de } 320 \text { Universidades } \\
\text { parceiras em todo o mundo. }\end{array}$ \\
\hline \multicolumn{2}{|c|}{ Quanto ao número de acadêmicos que já realizaram mobilidade acadêmica } \\
\hline 53 acadêmicos já realizaram mobilidade. & Cerca de 1200. \\
\hline \multicolumn{2}{|c|}{ Quanto aos países preferidos pelos acadêmicos para a realização da mobilidade } \\
\hline Portugal e Espanha. & Espanha, Polônia, França e República Checa. \\
\hline \multicolumn{2}{|c|}{ Quanto aos acadêmicos que estão atualmente em mobilidade acadêmica } \\
\hline $\begin{array}{l}\text { Atualmente } 6 \text { estudantes estão em mobilidade na } \\
\text { Espanha, Holanda e Inglaterra. }\end{array}$ & $\begin{array}{l}\text { Atualmente } 84 \text { estudantes estão em mobilidade na } \\
\text { Alemanha, Bélgica, Croácia, Dinamarca, Espanha, } \\
\text { França, Grécia, Holanda, Irlanda, Itália, Macau, } \\
\text { Polônia, Reino Unido e República Tcheca. }\end{array}$ \\
\hline \multicolumn{2}{|l|}{ Quanto aos cursos que oferecem mobilidade acadêmica } \\
\hline Todos os cursos oferecem mobilidade. & Com exceção do curso de Medicina, todos. \\
\hline \multicolumn{2}{|l|}{ Quanto ao tempo de estadia dos intercambistas no exterior } \\
\hline De 6 meses a 1 ano. & De 6 meses a 1 ano. \\
\hline \multicolumn{2}{|c|}{ Quanto ao aproveitamento de disciplinas cursadas no exterior } \\
\hline $\begin{array}{l}\text { Por lei, é necessário que o aluno autentique no } \\
\text { consulado da jurisdição em que ele estudou os } \\
\text { documentos referentes as matérias cursadas. Porém o } \\
\text { documento só é enviado para o aluno e para a Instituição } \\
\text { A cerca de } 2 \text { meses após o fim do intercâmbio, o que } \\
\text { tem gerado um problema no aproveitamento das } \\
\text { matérias. }\end{array}$ & $\begin{array}{l}\text { "A Instituição parceira envia um Transcript of } \\
\text { Records - TR (Histórico) com as classificações que } \\
\text { depois serão convertidas para classificações } \\
\text { nacionais, com base numa tabela publicada em } \\
\text { Diário da República." }\end{array}$ \\
\hline \multicolumn{2}{|c|}{ Quanto a idade média dos acadêmicos de realizam mobilidade acadêmica } \\
\hline De 21 a 23 anos. & Aproximadamente 20 anos. \\
\hline \multicolumn{2}{|l|}{ Outros tipos de acordos de mobilidade oferecidos } \\
\hline $\begin{array}{l}\text { Além do Santander e Ciência sem Fronteiras, a } \\
\text { Instituição A proporciona mobilidade acadêmica com } \\
\text { instituições parceiras (sem bolsa) para alunos dos cursos } \\
\text { de graduação e pós graduação. }\end{array}$ & $\begin{array}{l}\text { "Neste momento existem os Acordos Erasmus+; } \\
\text { Erasmus Mundus; Protocolos de Cooperação e já } \\
\text { tivemos no passado as Bolsas Santander que permitia } \\
\text { aos nossos estudantes saírem em Mobilidade para o } \\
\text { Brasil." }\end{array}$ \\
\hline
\end{tabular}

Fonte: Elaborado pelo autor (2016). 
De acordo com os dados obtidos na entrevista percebe-se que ambas as instituições divulgam a mobilidade acadêmica praticamente da mesma maneira, porém a Instituição B realiza Sessões de Esclarecimento periodicamente sobre os programas de mobilidade, ocasionando a ampla divulgação do tema entre os alunos, enquanto a Instituição A aborda o tema na recepção dos calouros.

Quanto as bolsas ofertadas aos acadêmicos das instituições, observa-se que ambas as instituições participam dos principais programas que ofertam bolsas para os acadêmicos dos dois países. A Instituição A conta atualmente com duas, a Bolsa Santander e o Ciência sem Fronteiras. Já a Instituição B conta com o Erasmus, que permite os alunos europeus a realizarem intercâmbio somente nos países pertencentes à União Europeia.

Em relação aos acordos das instituições em estudo com instituições no exterior, a Instituição B possui um maior número de acordos, contabilizados em 320, enquanto a Instituição A conta com apenas 29. Outra característica que apresenta divergência entre as duas instituições é o número de acadêmicos que já realizaram mobilidade de cada Universidade, visto que a Instituição A enviou 59 alunos para o exterior e possui 6 em processo de mobilidade, enquanto a Instituição B enviou cerca de 1200 e conta com 84 alunos no exterior.

De acordo com os gestores, a faixa etária dos acadêmicos de ambas as instituições que participaram de mobilidade também é a mesma (aproximadamente 20 anos), e o período de mobilidade também é em maioria 1 semestre. Todos os cursos das duas Universidades oferecem mobilidade acadêmica, com exceção do curso de Medicina da Instituição B.

Quanto ao processo de aproveitamento das disciplinas, enquanto a Instituição A exige que o acadêmico autentique, no consulado da jurisdição em que o mesmo estudou, os documentos originais emitidos pela instituição receptora, a Instituição $\mathbf{B}$, após receber o histórico com as médias da instituição do exterior, converte as mesmas para as classificações nacionais baseando-se em uma tabela presente no Diário da República.

\subsection{QUESTIONÁRIO ESTRUTURADO, APLICADO EM ACADÊMICOS QUE REALIZARAM MOBILIDADE ACADÊMICA}

Inicialmente apresenta-se o perfil dos acadêmicos investigados: Os estudantes da Instituição A realizam mobilidade entre 19 e 22 anos em sua maioria, são solteiros, não estão no mercado de trabalho e demonstram estar matriculados nos cursos de Comércio Exterior e Psicologia, seguido por Direito e Engenharia Civil. Os alunos ficam um semestre em 


\section{MOBILIDADE ACADÊMICA: UM ESTUDO COMPARATIVO NO CONTEXTO DE INSTITUIÇÕES UNIVERSITÁRIAS \\ DOI: http://dx.doi.org/10.5007/1983-4535.2017v10n4p252}

mobilidade e os países de destino predominantes são Espanha e Portugal. Percebe-se que o fator do idioma influencia o destino dos intercambistas.

Quanto ao perfil dos acadêmicos da Instituição B que realizam mobilidade acadêmica, observa-se que os alunos têm entre 20 e 22 anos, são solteiros, não estão no mercado de trabalho e são em maioria estudantes de Gestão de Empresas e Economia. Ficam 1 semestre em mobilidade principalmente em países como Polônia, Espanha e República Tcheca. Nota-se que estes países pertencem à União Europeia, e mostra que os objetivos de consolidação de uma dimensão europeia de educação proposto pelo programa Erasmus estão sendo executados (UNIVERSIDADE NOVA DE LISBOA, 2007).

Quadro 2 Quadro comparativo das opiniões dos acadêmicos.

\begin{tabular}{|c|c|}
\hline Instituição A & Instituição B \\
\hline \multicolumn{2}{|c|}{ Quanto a forma do conhecimento da existência da mobilidade acadêmica } \\
\hline $\begin{array}{l}\text { Através da mídia da Universidade; e-mail do setor de } \\
\text { Relações internacionais; divulgação em sala por parte } \\
\text { do Coordenador do curso. }\end{array}$ & $\begin{array}{ll}\text { Através de } & \text { relatos de amigos que realizaram } \\
\text { mobilidade; } & \text { Universidade; internet; colegas e } \\
\text { professores. } & \end{array}$ \\
\hline \multicolumn{2}{|c|}{ Quanto a divulgação da mobilidade acadêmica na Universidade } \\
\hline $\begin{array}{l}\text { A mobilidade acadêmica não é bem divulgada na } \\
\text { Universidade, falta informação. }\end{array}$ & É bem divulgada na Universidade. \\
\hline \multicolumn{2}{|c|}{ Quanto aos motivos que levaram os acadêmicos a realizar a mobilidade } \\
\hline $\begin{array}{l}\text { Conhecer outras culturas, idiomas, e experiência de } \\
\text { vida pessoal, acadêmica e profissional; vontade de } \\
\text { viajar. }\end{array}$ & $\begin{array}{l}\text { Conhecer outras culturas, idiomas, e experiência de } \\
\text { vida pessoal, acadêmica e profissional; vontade de } \\
\text { viajar; sair da zona de conforto. }\end{array}$ \\
\hline \multicolumn{2}{|c|}{ Quanto as dificuldades e desafios encontrados durante a mobilidade } \\
\hline $\begin{array}{l}\text { Falta de auxilio e informação do setor de Relações } \\
\text { Internacionais; dificuldade para encontrar acomodação } \\
\text { e retirar o visto; validação das matérias; dificuldade } \\
\text { em fazer amizades; idioma; saudade da família e } \\
\text { amigos; administrar o valor da bolsa; adaptação. }\end{array}$ & $\begin{array}{l}\text { Burocracia, idioma, adaptação; administrar o valor da } \\
\text { bolsa e equivalências. }\end{array}$ \\
\hline \multicolumn{2}{|c|}{ Quanto ao processo de aproveitamento das disciplinas } \\
\hline $\begin{array}{l}\text { Considerado um desafio para os estudantes. A maioria } \\
\text { em processo de aproveitamento ou sem } \\
\text { aproveitamento nenhum. Apenas } 2 \text { acadêmicos } \\
\text { conseguiram aproveitar algumas matérias, sem } \\
\text { aproveitamento total. }\end{array}$ & $\begin{array}{l}\text { A maioria obteve total aproveitamento, a minoria } \\
\text { obteve aproveitamento quase total. }\end{array}$ \\
\hline \multicolumn{2}{|c|}{ Quanto ao suporte e apoio da Universidade de origem do acadêmico durante a mobilidade } \\
\hline $\begin{array}{l}\text { Insuficiente. Setor despreparado, ineficiente, } \\
\text { desinformado, não sana as dúvidas dos acadêmicos e } \\
\text { não oferece suporte. }\end{array}$ & $\begin{array}{l}\text { Hove suporte e apoio da Universidade de origem } \\
\text { durante a mobilidade. }\end{array}$ \\
\hline \multicolumn{2}{|c|}{ Quanto as melhorias que poderiam ser implantadas na Universidade de origem } \\
\hline $\begin{array}{l}\text { Oferecer maior auxilio e acompanhamento do } \\
\text { estudante; abertura de mais editais e mais bolsas; } \\
\text { maior divulgação e exposição da mobilidade } \\
\text { acadêmica; melhor qualificação profissional dos } \\
\text { funcionários da Instituição A (incluindo professores } \\
\text { para receber intercambistas); melhor interação entre o } \\
\text { setor de Relações Internacionais e o departamento }\end{array}$ & $\begin{array}{l}\text { Ajuda monetária; implantação do ensino também em } \\
\text { inglês, maior interação de alunos locais e } \\
\text { internacionais; palestras com relatos de experiências } \\
\text { de mobilidade; mudança no método de avaliação. }\end{array}$ \\
\hline
\end{tabular}




\begin{tabular}{|c|c|}
\hline $\begin{array}{l}\text { Acadêmico; melhor política de aproveitamento das } \\
\text { disciplinas; lista de acomodações; realização de } \\
\text { entrevista pós intercâmbio afim de coletar informações } \\
\text { sobre o destino para ajudar o próximo acadêmico; } \\
\text { incentivo de atividades extracurriculares; mais rigidez } \\
\text { nas provas e trabalhos; gravação de aulas para estudo } \\
\text { domiciliar; estimular alunos para fala de outro idioma. }\end{array}$ & \\
\hline \multicolumn{2}{|c|}{ Quanto ao tipo de mobilidade realizada pelo acadêmico (bolsas ou acordos) } \\
\hline Predominantemente Bolsa Santander. & Predominantemente Bolsa de Erasmus. \\
\hline uanto as bolsas oferecidas pela Universida & le origem que o acadêmico tem conhecimento \\
\hline
\end{tabular}

Fonte: Elaborado pelo autor (2016).

Os resultados alcançados demonstram que há uma divergência quanto a divulgação da existência de programas de mobilidade acadêmica nas Instituições. Enquanto a Instituição A divulga principalmente através da mídia da Universidade e é considerada ruim pelos acadêmicos, na Instituição $\mathbf{B}$ o assunto é mais difundido devido a grande quantidade de acadêmicos que realizaram mobilidade, tornando esses programas algo habitual na Instituição, além de ser considerada bem divulgada.

Nota-se que os motivos que levaram estes acadêmicos a realizar mobilidade foram praticamente os mesmos. Os alunos de ambas as insituições citam a vontade de conhecer novas culturas e idiomas; a experiência de vida pessoal, acadêmica e profissional e a vontade de viajar. Alguns respondentes da Instituição B também foram motivados pela vontade de testar sua capacidade de adaptação, saindo da zona de conforto, que pode caracterizar uma pré disposição que os alunos deste país possuem para se tornarem independentes, contribuindo com o grande número de alunos que passam um período fazendo mobilidade.

Identificou-se uma forte dificuldade dos alunos da Instituição A em relação às informações e auxílio que o setor de Relações Internacionais da Universidade deveria prestar aos acadêmicos. A falta de auxílio e informação por parte da Instituição A foi citada como a maior dificuldade e desafio dos alunos. A obtenção do visto e saudade da família e amigos também foram mencionadas pelos acadêmicos desta instituição. Quanto às dificuldades em comum encontradas pelos acadêmicos de ambas as instituições, foram indicados o idioma do país de destino; a adaptação e assuntos relacionados às disciplinas cursadas. Para a instituição brasileira, a dificuldade foi em relação ao processo de aproveitamento das matérias. Para a instituição portuguesa, a dificuldade foi encontrar matérias com as mesmas equivalências das disciplinas na Universidade de origem. Além disso, a burocracia envolvida no processo de mobilidade foi muito citada pelos acadêmicos da Instituição $\mathbf{B}$.

Dos respondentes da Instituição $\mathbf{A}$, apenas 2 acadêmicos conseguiram realizar o aproveitamento de algumas matérias, não houve aproveitamento total. $\mathrm{O}$ restante não conseguiu efetivar o aproveitamento das matérias realizadas no exterior ou ainda encontra-se em processo de aproveitamento. Quanto aos alunos da Instituição B, todos eles conseguiram realizar o aproveitamento das disciplinas realizadas na instituição de mobilidade. A grande maioria conseguiu validar todas as disciplinas, e a minoria que não conseguiu aproveitar todas, alega que o motivo foi o idioma do país de destino e o pouco aproveitamento das matérias no exterior. Observa-se uma grande divergência quanto as estatísticas de aproveitamento de disciplinas cursadas no exterior das duas instituições, onde há uma grande dificuldade de validar as matérias na Instituição A, ao contrário da Instituição B, em que todos os alunos conseguem realizar o aproveitamento das mesmas. 
Também houve divergência nas respostas dos acadêmicos das duas instituições quando questionados sobre o suporte oferecido pelas instituições de origem durante a mobilidade. Os acadêmicos da Instituição A consideram o suporte oferecido pelo setor de Relações Internacionais insuficiente, e justificam que o setor é despeparado, ineficiente e não sana as dúvidas dos acadêmicos em relação ao processo de mobilidade, não oferecendo o suporte necessário. Para os alunos da Instituição B, o setor de Relações Internacionais ofereceu o auxílio necessário para a realização do intercâmbio dos mesmos, com exceção de 4 alunos que argumentam que o auxilio oferecido foi insuficiente.

Entre as melhorias sugeridas pelos acadêmicos da Instituição A na própria instituição, a mais mencionada foi em relação à carência de auxílio que a Universidade deveria prestar aos acadêmicos em mobilidade. Em relação a este tópico, além do suporte que deveria ser oferecido, os alunos propõem a elaboração de uma lista de possíveis acomodações no destino de mobilidade (observa-se que a acomodação no exterior está entre uma das dificuldades citadas); assim como o recolhimento de informações úteis do acadêmico que retornou do intercâmbio para que a instituição possa auxiliar melhor o próximo acadêmico com o mesmo destino deste. Os alunos também sugerem uma melhor e maior divulgação dos programas de mobilidade, assim como um número maior abertura de editais e bolsas. É possível identificar que as melhorias propostas pelos alunos vão de encontro com as dificuldades encontradas pelos mesmos.

Além destas sugestões, os acadêmicos também sentem uma falta de preparação e qualificação dos profissionais da Insituição A, e recomendam que os mesmos sejam melhor preparados para atender os alunos, inclusive intercambistas. Em relação à dificuldade encontrada pelos alunos para realizar o aproveitamento das disciplinas cursadas no exterior, eles sugerem que haja uma melhor interação entre o setor de Relações Internacionais e o departamento Acadêmico, e uma melhor política de aproveitamento das disciplinas. Por fim, em relação aos estudos, são sugeridos o maior incentivo de atividades extracurriculares, mais rigidez nas provas e trabalhos; gravação de aulas para estudo domiciliar e o estímulo dos alunos para fala de outro idioma.

Já os alunos da Instituição $\mathbf{B}$ sentem a necessidade de maior ajuda monetária no programa de mobilidade. A opção do ensino em inglês em todas as disciplinas também é sugerido pelos mesmos, dada a dificuldade que encontraram nos idiomas dos países de destino, tendo o conhecimento que sua instituição de origem também recebe muitos intercambistas. A maior interação de alunos locais e internacionais e a realização de palestras com relatos de experiências de mobilidade também fazem parte das melhorias propostas, assim como a mudança no método de avaliação.

Percebe-se que há uma forte relação entre as melhorias sugeridas pelos acadêmicos de ambas as instituições e as dificuldades enfrentadas pelos mesmos no destino de mobilidade. A quantidade de melhorias propostas pelos alunos da Instituição A é muito maior que o número de melhorias sugeridas pelos acadêmicos da Instituição $\mathbf{B}$, o que leva a crer que há muito mais a ser trabalhado e qualificado na universidade brasileira do que na universidade portuguesa.

Em relação aos custos financeiros dos programas de mobilidade realizados pelos respondestes, a maioria dos acadêmicos da Instituição $\mathbf{A}$ foram contemplados com Bolsas Santander, onde somente a minoria realizou mobilidade proveniente de acordos entre as instituições, em que a responsabilidade sobre os custos é inteiramente do aluno. Ocorre o mesmo na Instituição B , onde os alunos foram contemplados com Bolsa Erasmus. Observa-se 
que em ambas as universidades a maioria dos programas de intercâmbio são realizadas através de bolsas.

Quando questionados a que tipos de bolsas de mobilidade a instituição de origem oferece aos acadêmicos, a maioria dos respondentes da Instituição A citaram que conhecem uma ou outra de todas as bolsas ofertadas (Bolsa Santander e Ciência sem Fronteiras),e alguns responderam que conhecem ambas. O mesmo ocorre com os alunos da Instituição $\mathbf{B}$, que em geral também possuem conhecimento sobre as bolsas ofertadas (principalmente Bolsa Erasmus e também Fullbright).

\section{CONCLUSÃO}

Observou-se que as duas instituições analisadas possuem alguns pontos de convergência, onde pode-se citar os programas de bolsas de mobilidade que ambas recebem para ofertá-las aos alunos, o período que estes acadêmicos passam no exterior, assim como o perfil dos mesmos. Ambas as universidades possuem acordos bilaterais, recebem e enviam intercambistas.

Pressupõe-se que a Instituição A necessita melhorar vários pontos relacionados ao envio de acadêmicos para o exterior, iniciando pela preparação dos mesmos para enfrentar este período fora do país, auxiliando-os em toda e qualquer situação: antes, durante e após a realização da mobilidade acadêmica. A Instituição deve também rever sua política de aproveitamento de disciplinas cursadas em Instituições estrangeiras, a fim de haver um melhor aproveitamento das mesmas pelos acadêmicos que retornarem de mobilidade acadêmica, visto que a política atual dificulta este procedimento e pode caracterizar uma barreira para o envio de novos alunos ao exterior.

Observou-se que a Instituição A deveria disponibilizar mais editais e assinar mais acordos com instituições estrangeiras com o objetivo de obter uma maior internacionalização, e investir fortemente na divulgação de seus programas de mobilidade, acordos e bolsas que são ofertadas aos seus acadêmicos.

Em relação à Instituição B, conclui-se que a mesma já possui um bom nível de internacionalização e está no caminho certo para a excelência de internacionalização do ensino oferecido aos seus acadêmicos, com poucos pontos que possuem a necessidade de serem melhorados, como a diminuição da burocracia para a realização dos programas de mobilidade, uma maior interação entre intercambistas e alunos e o quesito financeiro dos programas de mobilidade.

\section{REFERÊNCIAS BIBLIOGRÁFICAS}

ALTBACH, P. G.; KNIGHT, J. The internationalization of higher education: motivations and realities. Journal of studies in international education, v. 11, n. 3-4, p. 290-305, Fall/Winter 2007.

BOHRER, I. N.; PUEHRINGER, J. O.; SILVA, D. S.; NAIRDOF, J. A história das universidades: o despertar do conhecimento. 10 f. Buenos Aires, 2008. Disponível em: <http://www.unifra.br/eventos/jne2008/Trabalhos/114.pdf>. Acesso em: 18 set. 2015. 
BRASIL. Ciências sem fronteiras. 2015 a. Disponível em: <http://www.cienciasemfronteiras.gov.br/web/csf/o-programa >. Acesso em: 10 set. 2015.

. Ministério da Educação, MEC. O Prouni. 2015b. Disponível em:

<http://siteprouni.mec.gov.br/o_prouni.php>. Acesso em: 10 out. 2015.

DOMINGUES, M. J. C. S; RABOCH, H. A Internacionalização do Ensino Superior: o caso da Universidade Regional de Blumenau. 172 EPA - VI Simpósio de Gestão e Estratégia em Negócios Seropédica, RJ, Brasil, Setembro de 2008.

DUARTE, R. G.; DE LIMA JÚNIOR, A. F.; BATISTA, R. V. L. O processo de internacionalização das instituições de ensino superior: o caso das Pontifícias Universidades Católicas de Minas Gerais e do Paraná. Revista Economia \& Gestão, v. 7, n. 14, p. 159-162, 2008.

FRANKLIN, L. A. S. O processo de internacionalização do ensino superior no Brasil: um estudo de caso na Universidade Federal de Viçosa. 2014. 79 f. Monografia (Bacharel em Secretariado Executivo Trilíngue) Universidade Federal de Viçosa. Viçosa, 2014.

JACA, C.; FREITAS, J. Linhas gerais sobre a história da universidade

conimbricense: Das suas origens à reforma universitária pombalina de 1772. 2008.

Disponível em:

http://www.esas.pt/jaca/docs/Historia\%20da\%20Universidade\%20Conimbricense.pdf.

Acesso em: 20 set. 2015

LIMA, M. C.; RIEGEL, V. A influência da mobilidade acadêmica sobre a formação dos jovens. Negócios e Talentos, Porto Alegre, v. 2, n. 11, p. 70-80, 2013. Disponível em: < http://seer.uniritter.edu.br/index.php/negocios/article/viewArticle/675> . Acesso em: 05 set. 2015.

PORTUGAL. Ministério da Educação. Uma estratégia para a internacionalização do ensino superior português. Portugal, 2014. Disponível

em: <http://www.portugal.gov.pt/pt/os-ministerios/ministerio-da-educacao-e-

ciencia/documentos-oficiais/20140926-mec-internacionalizacao-ensino-superior.aspx $>$.

Acesso em: 06 set. 2015.

Ministério da Educação. Breve evolução histórica do sistema educativo. 2003.

Disponível em: <http://www.oei.es/quipu/portugal/historia.pdf>. Acesso em: 01 out. 2015.

ROSSATO, R. Universidade Brasileira: novos paradigmas institucionais emergentes. In: ISAIA, S. M. de A.; BOLZAN, D. P. V.; MACIEL, A. M. da R.. Qualidade da educação superior: a universidade como lugar de formação. Porto Alegre: EDIPUCRS, 2011.

SAMPAIO, B.; GUIMARÃES, J. Diferenças de eficiência entre ensino público e privado no Brasil. Economia Aplicada, São Paulo, v. 13, n. 1, p. 45-68, Janeiro - Março 2009.

Disponível em: <http://www.scielo.br/pdf/ecoa/v13n1/v13n1a03.pdf>. Acesso em: 07 set. 2015.

SANTANDER UNIVERSIDADES. Programas de Bolsas de Estudo. 2016. Disponível em: $<$ https://www.santanderuniversidades.com.br/bolsas/Paginas/default.aspx >. Acesso em: 10 set. 2016.

SANTOS, A. P. dos; CERQUEIRA, E. A. de. Ensino superior: trajetória histórica e políticas recentes. In: IX Colóquio Internacional sobre Gestão Universitária na América do Sul. 
Florianópolis, 2009. Disponível em: <https://repositorio.ufsc.br/handle/123456789/35836>. Acesso em: 10 set. 2015.

SANTOS, F. S.; ALMEIDA FILHO, N. de. A quarta missão da universidade: internacionalização universitária na sociedade do conhecimento. Imprensa da Universidade de Coimbra e UNB, 2012.

SIEBIGER, R. H. O processo de Bolonha e os novos espaços transnacionais de educação superior latino-americanos: a universidade brasileira em movimento. Cadernos

PROLAM/USP, São Paulo, v. 9, n. 17, p. 119-135, 2010. Disponível em:

<http://www.revistas.usp.br/prolam/article/view/82439>. Acesso em: 06 set. 2015.

STALLIVIERI, L. O processo de internacionalização nas instituições de ensino superior. Educação Brasileira: Revista do Conselho de Reitores das Universidades Brasileiras, Brasília, v. 24, n. 48, 2002.

TEICHLER, U. The Changing debate on Internationalization of higher education. Higher Education. $n^{\circ}$ 48. 2004.

TRINDADE, H. Saber e poder: os dilemas da universidade brasileira. Estudos Avançados, São Paulo, v. 14, n. 40, p. 122-133, 2000. Disponível em:

$<$ http://www.scielo.br/scielo.php?pid=S0103-

40142000000300013\&script=sci_arttext\&tlng=pt>. Acesso em: 04 set. 2015.

UNIVERSIDADE DO ALGARVE. História. 2016. Disponível em:

<https://www.ualg.pt/pt/content/sobre-ualg>. Acesso em: 20 mar. 2016.

UNIVERSIDADE DO EXTREMO SUL CATARINENSE. Histórico. 2016. Disponível em: <http://www.unesc.net/portal/capa/index/91/5085>. Acesso em: 20 mar. 2016.

UNIVERSIDADE NOVA DE LISBOA. Programa Erasmus/Sócrates. 2007. Disponível em: 〈http://www.unl.pt>. Acesso em: 15 set. 2015.

VILALTA, L. A. A internacionalização do ensino superior brasileiro: conceito e características do processo em instituições privadas de ensino superior. [Tese de Doutorado, PUC-SP]. São Paulo, 2012. 